\title{
Characterization of Irradiation Induced Mutants of Cassava (Manihot esculenta Crantz) Generated from Jame-jame and Adira-4 Genotypes at $M_{1} V_{2}$ Generation
}

\section{Nurul Khumaida, Sintho Wahyuning Ardie, and Mira Sri Astuti}

Department of Agronomy and Horticulture, Faculty of Agriculture Bogor Agricultural University (IPB) Jl. Meranti, Kampus IPB Darmaga, Bogor 16680, Indonesia

\section{Abstract}

Cassava (Monihot esculento Crantz., Euphorbiaceae) is an important dietary carbohydrate source for approximately 800 million people in the tropics. It is a potential crop for food, feed, and industry. Cassava breeding through conventional approaches are hampered with some limitations which resulted in a low number of

Corresponding Author: Nurul Khumaida

Received: 28 July 2017

Accepted: 14 September 2017 Published: 23 November 2017

Publishing services provided by Knowledge E

(c) Nurul Khumaida et al. This article is distributed under the terms of the Creative

commons Attribution License,

which permits unrestricted

use and redistribution

provided that the original

author and source are credited.

Selection and Peer-review under the responsibility of the ICSAFS Conference Committee.

\section{G OPEN ACCESS} superior varieties. The objective of this research was to generate several mutant lines with higher yield and starch content. This research intended to identify the second generation $\left(M_{1} V_{2}\right)$ Jame-jame and Adira-4 variant cassava mutants from gamma ray irradiation. Jame-jame is a local genotype from Halmahera (local high yielding genotype, sweet, and potential) and Adira-4 is an Indonesia national variety of cassava. Mutant diversity appears on the plant height, plant branching, and plant tubers that harvested at 10 months after planting (MAP). Our results showed the positive correlation between plant height, first branching height, tuber weight, number of roots, and number of economic roots. Based on tuber weight and number of economic tuber there were 9 potential mutants (putative). Based on the stability test, there were 6 potential stable mutants (putative) by first branching height, tuber weight, total number of tubers, and total number of economies tuber, namely: $V_{5} D 1-(2), V_{5} D 1-2(2), V_{5} D 1-3(2), V_{5} D 1-4(3), V_{5} D 2-2(2)$, and $V_{5} D 2-6(2)$.

Keywords: local genotype, $M_{1} V_{2}$, storage root, characters, stability.

\section{Introduction}

The import value of wheat based products is still on the first rank of food and agricultural products list in Indonesia, and it continues to increase year by year. Therefore, a breakthrough and efficient strategy are needed to reduce wheat import. One effort that can be done is to optimize and raise alternative sources of carbohydrates from tuberous crops such as cassava (Monihot esculento Crantz.).). In Indonesia, from 20112014 the average of cassava planting area 1,100,000 ha, with production of 24,200,000 
ton, and average productivity of 22 ton ha ${ }^{-1}$. Cassava is an important dietary carbohydrate source for approximately 800 million people in the tropics [1]. Africa is the major producer of cassava worldwide, followed by Asia and Latin America, with total production around 200 million ton [2]. In the global trade of cassava, Thailand and Indonesia are the major cassava exporters; exporting mainly cassava chips, cassava pellets, cassava starch, and flour. More recently, it has gained importance as a possible fuel commodity not only in Indonesia but also in Philippines, China, Thailand, and other countries which have more advanced national bio-fuel programs. It is a competitive source of starch; cassava is the second most important source of starch worldwide, after maize and is the starch most traded internationally $[3,4]$.

Despite the high demand of cassava for food and industry, there is a large gap between the potential yield and actual yields in farmers' fields suggesting that the highest potential of cassava production is far from being reached with traditional varieties, usually cultivated on marginal soils without inputs. Moreover, cassava breeding through conventional approaches are hampered with some limitations which resulted in a low number of superior cassava varieties. Therefore, mutation breeding and the use of molecular marker in the cassava breeding program should fasten the superior cassava varieties development, especially with high yield and abiotic stress tolerance traits.

Asexually propagated crops offer the advantage that all genetic effects can be exploited in farmers' production fields. However, non-additive effects complicate selection because, while influencing the performance of the materials under evaluation, they cannot be transmitted efficiently to the following cycle of selection. Cassava be used as a model crop for asexually propagated crops because of its diploid nature and the absence of (known) incompatibility effects [5].

The objective of the research was to generate several mutant lines with higher yield and starch content of several irradiated cassava. Identification and evaluation of several characters, i.e. growth and yield were performed on population of $M_{1} V_{2}$.

\section{Materials and Method}

The research was conducted in university experimental field, Bogor Agricultural University (240 m asl) in 2013-2014. Gamma ray irradiation treatment was applied in the Laboratory of Isotope Technology Application Center and Irradiation (PATIR), National Nuclear Energy Agency (BATAN), South Jakarta, Indonesia. The planting materials used were nine months cassava cuttings, with five buds of $M_{1} V_{2}$ generation.

The research was arranged in a randomized complete block design (RCBD) with one factor. The factor was the cassava genotypes, i.e. Jame-jame and Adira 4 both were parent lines, and 43 mutant lines. Jame-jame is a local genotype from Halmahera which 
is high yielding, sweet taste, and potential to be developed). Each block consisted of five stem cuttings, thus there were 135 experimental unit and 675 plants.

Irradiated cassava cuttings ( $M_{1} V_{2}$ generation) were planted in the university experimental field, with $1 \mathrm{~m} \times 1 \mathrm{~m}$ plant spacing. Cassava plants were fertilized with urea, $\mathrm{SP}-36$, and $\mathrm{KCl}$ with the rate of 200,150 , and $150 \mathrm{~kg} \mathrm{ha}^{-1}$, respectively. SP-36 fertilizer was given entirely at planting time, Urea was given $1 / 3$ of the rate at planting and $2 / 3$ of the rate at the age of one month after planting (MAP), whereas $\mathrm{KCl}$ was given at 2-3 MAP. Weeds were manually controlled every 4 weeks. Soil ridging was conducted in conjunction with the second application of Urea fertilizer. The growth observation was done at every month i.e. Plant height, number of leaf, and stem diameter. However, the yield characters, i.e. number of tuber, number of economic tubers and weight of fresh tuber were analyzed at the day of harvesting, 9 months after planting.

\section{Results and Discussions}

This research intended to identify and evaluate the second generation $\left(M_{1} V_{2}\right)$ of Jamejame and Adira-4 variant cassava mutants from gamma ray irradiation. Jame-jame is local genotype from North Halmahera (east part of Indonesia), while Adira-4 is national variety. Table 1 shows the results of mean value of yield variables from both genotypes, the Jame-jame $\left(V_{1}\right)$ and Adira-4 $\left(V_{5}\right)$ mutants. The yield characters were evaluated at the day of harvesting. Highest number of tubers from Jame-jame mutant genotypes was 22 tubers on $\mathrm{V}_{1} \mathrm{D}_{2}$-5(2) genotypes, which was significantly different from parent line, Jame-jame genotypes (11.7 tubers). The lowest number of tubers was 4 tubers on $V_{1} D_{1}-4(2)$. The highest number of economic tubers was 15.0 tubers from $V_{1} D_{1}-6(2)$, which is significantly higher than the Jame-jame genotype (6.3 tubers).

Furthermore, in the Adira- 4 mutants, the highest number of tuber was 18 tubers on $V_{5} D_{2}-2(2)$, significantly different with Adira-4 variety (7.7 tubers). However, in the Adira-4 mutants, the highest number of economic tubers was 14.0 tubers also from $V_{5} D_{2}-2(2)$, significantly different with parent line only 4 tubers. Based on these data, appears that the highest number of tubers is not followed by the number of economic tubers anyway, because the tubers that calculated as the number of tubers are the tubers with a length more than $5 \mathrm{~cm}$. The same result of number of tuber and number of economic tubers on other genotype (Ratim, UJ-5, and Malang-4) at M1V2 generation also reported by Khumaida et al. [6]. Table 1 also shows the fresh tuber per plant of 43 mutants and 2 parent lines (Jame-jame and adira-4) $M_{1} V_{2}$ generation. The heaviest tuber weight per plant are $6.02 \mathrm{~kg}$ and $12.92 \mathrm{~kg}$ obtained in $\mathrm{V}_{1} \mathrm{D}_{2}-(1)$ and $\mathrm{V}_{5} \mathrm{D}_{2}-6(2)$ genotype respectively, which were heavier than parent lines. It appears that, some yield characters of cassava in the generation $M_{1} V_{2}$ still vary widely and need to be improved and stabilized in the next generation. 
TABLE 1: Yield characters of several mutant lines $M_{1} V_{2}$ generation.

\begin{tabular}{|c|c|c|c|c|c|c|c|}
\hline \multirow[t]{2}{*}{ Genotype } & \multicolumn{3}{|c|}{ Jame-jame } & \multirow[t]{2}{*}{ Genotype } & \multicolumn{3}{|c|}{ Adira-4 } \\
\hline & $\begin{array}{c}\text { Tuber } \\
\text { weight per } \\
\text { plant (kg) }\end{array}$ & $\begin{array}{c}\text { Number of } \\
\text { tuber per } \\
\text { plant }\end{array}$ & $\begin{array}{l}\text { Number of } \\
\text { economic } \\
\text { tubers }\end{array}$ & & $\begin{array}{c}\text { Tuber } \\
\text { weight per } \\
\text { plant (kg) }\end{array}$ & $\begin{array}{l}\text { Number of } \\
\text { tuber per } \\
\text { plant }\end{array}$ & $\begin{array}{l}\text { Number of } \\
\text { economic } \\
\text { tubers }\end{array}$ \\
\hline V1Do & $3.90 a b$ & 11.7 efghi & 6.3 defg & V5Do & $5.98 \mathrm{bcd}$ & $7.7 \mathrm{~d}$ & 4.0 ef \\
\hline$V_{1} D_{1}-(3)$ & $4.17 \mathrm{ab}$ & 15.7 bcde & $11.7 \mathrm{abc}$ & $V_{5} D_{1}-(2)$ & 8.32 abcd & $15 \cdot 3 \mathrm{ab}$ & $8.3 \mathrm{bcd}$ \\
\hline$V_{1} D_{1-1}(1)$ & $5.20 \mathrm{ab}$ & $20.0 \mathrm{ab}$ & $13.0 \mathrm{ab}$ & $V_{5} D_{1-1}(1)$ & $5.60 \mathrm{bcd}$ & $14.5 \mathrm{ab}$ & $4.0 \mathrm{ef}$ \\
\hline$V_{1} D_{1-1}(2)$ & $2.56 \mathrm{~b}$ & 17.0 abcd & 6.0 defg & $V_{5} D_{1-1(2)}$ & $9.79 a b c$ & $17.0 \mathrm{ab}$ & 7.0 cde \\
\hline$V_{1} D_{1}-1(3)$ & $3.15 a b$ & $7.0 \mathrm{ij}$ & $3.0 \mathrm{gh}$ & $V_{5} D_{1-1}(3)$ & $4.08 d$ & $11.0 \mathrm{bcd}$ & $2.0 \mathrm{f}$ \\
\hline$V_{1} D_{1}-2(2)$ & $6.06 a b$ & $10.0 \mathrm{fghi}$ & $9.0 \mathrm{bcde}$ & $V_{5} D_{1-2(1)}$ & $6.60 \mathrm{bcd}$ & $11.0 \mathrm{bcd}$ & $6.0 \mathrm{cde}$ \\
\hline$V_{1} D_{1}-2(3)$ & $5.17 a b$ & 14.5 cdef & 7.0 defg & $V_{5} D_{1-2(2)}$ & $9.71 a b c$ & $16.0 \mathrm{ab}$ & $11.0 \mathrm{ab}$ \\
\hline$V_{1} D_{1-3}(2)$ & $4.83 a b$ & 15.0 bcdef & 8.0 cdef & $V_{5} D_{1-3}(2)$ & $9.89 a b$ & $12.0 \mathrm{abcd}$ & $11.0 \mathrm{ab}$ \\
\hline $\mathrm{V}_{1} \mathrm{D}_{1-3}(3)$ & $5.22 \mathrm{ab}$ & 14.5 cdef & $10.5 \mathrm{bcd}$ & $V_{5} D_{1-3}(3)$ & $7.01 \mathrm{bcd}$ & $15 \cdot 3 \mathrm{ab}$ & $9.3 \mathrm{bc}$ \\
\hline$V_{1} D_{1-4}(2)$ & $3.28 \mathrm{ab}$ & $4.0 j$ & $3.0 \mathrm{gh}$ & $V_{5} D_{1-4}(2)$ & $6.77 \mathrm{bcd}$ & $13.0 \mathrm{abcd}$ & 7.0 cde \\
\hline$V_{1} D_{1}-5(2)$ & $4.69 a b$ & $20.0 \mathrm{ab}$ & $10.0 \mathrm{bcd}$ & $V_{5} D_{1-4}(3)$ & $8.72 \mathrm{abcd}$ & $15.0 \mathrm{ab}$ & 8.0 bcd \\
\hline$V_{1} D_{1}-5(3)$ & $3.02 \mathrm{~b}$ & $19.0 \mathrm{abc}$ & $10.0 \mathrm{bcd}$ & $V_{5} D_{1-5}(2)$ & $6.29 \mathrm{bcd}$ & $8.0 \mathrm{~cd}$ & $2.0 \mathrm{f}$ \\
\hline$V_{1} D_{1}-6(2)$ & $3.00 \mathrm{~b}$ & 12.0 defghi & $15.0 \mathrm{a}$ & $\left.V_{5} D_{1-5}-3\right)$ & $8.47 \mathrm{abcd}$ & $14.5 \mathrm{ab}$ & 6.0 cde \\
\hline$V_{1} D_{1}-6(3)$ & $3.59 a b$ & 9.7 fghi & $4.0 \mathrm{fgh}$ & $\mathrm{V}_{5} \mathrm{D}_{2}-(1)$ & $6.39 \mathrm{bcd}$ & $14.0 \mathrm{abc}$ & 7.7 bcde \\
\hline$V_{1} D_{1}-7(3)$ & $3.99 \mathrm{ab}$ & 8.0 hij & $4.0 \mathrm{fgh}$ & $V_{5} D_{2}-2(2)$ & $8.81 \mathrm{abcd}$ & $18.0 \mathrm{a}$ & $14.0 \mathrm{a}$ \\
\hline $\mathrm{V}_{1} \mathrm{D}_{2}-(1)$ & $6.02 \mathrm{a}$ & 12.5 defgh & 6.5 defg & $V_{5} D_{2}-2(3)$ & $4.89 \mathrm{bcd}$ & $7.0 \mathrm{~d}$ & 5.0 def \\
\hline$V_{1} D_{2}-(2)$ & $4.05 a b$ & 10.7 efghi & $4.3 \mathrm{fgh}$ & $V_{5} D_{2}-3(3)$ & $6.83 \mathrm{bcd}$ & $15 \cdot 3 a b$ & 6.7 cde \\
\hline $\mathrm{V}_{1} \mathrm{D}_{2}-1(2)$ & $3.91 \mathrm{ab}$ & 13.0 defgh & $1.0 \mathrm{~h}$ & $V_{5} D_{2-4}(2)$ & $4.85 \mathrm{bcd}$ & $8.0 \mathrm{~cd}$ & 5.0 def \\
\hline$V_{1} D_{2}-2(2)$ & $3.87 a b$ & 9.0 ghi & 5.0 efgh & $V_{5} D_{2}-4(3)$ & $4.82 \mathrm{~cd}$ & $11.3 \mathrm{bcd}$ & 7.7 bcde \\
\hline$V_{1} D_{2}-4(3)$ & $3.17 a b$ & 14.0 cdefg & $3.0 \mathrm{gh}$ & $V_{5} D_{2}-5(3)$ & $7.64 \mathrm{bcd}$ & $11.3 \mathrm{bcd}$ & 5.0 def \\
\hline$V_{1} D_{2}-5(2)$ & $5.12 a b$ & $22.0 \mathrm{a}$ & $10.0 \mathrm{bcd}$ & $V_{5} D_{2}-6(2)$ & $12.92 \mathrm{a}$ & $8.0 \mathrm{~cd}$ & $8.0 \mathrm{bcd}$ \\
\hline$V_{1} D_{2}-6(3)$ & $4.31 \mathrm{ab}$ & 15.0 bcdef & $10.3 \mathrm{bcd}$ & $V_{5} D_{3}-(1)$ & $6.76 \mathrm{bcd}$ & $10.7 \mathrm{bcd}$ & 5.7 cdef \\
\hline$V_{1} D_{2}-7(3)$ & $4.46 a b$ & 13.0 defgh & $12.0 \mathrm{abc}$ & & & & \\
\hline
\end{tabular}

Note: Value from the same colomn followed with the same letter is not significantly different in $5 \%$ test level (Duncan Multiple Range Test)

Table 2 shows the correlation between variables on the mutant from Jame-jame and Adira-4 genotypes. Based on correlation analysis on both genotypes, it appears that plant height positively correlated highly significant with height to the first branching, suggests that increasing of plant height will increase the height to the first branching also. The number of tuber had a significant positive correlation with the number of economic tuber characters, which increasing of number of tubers per plant would increase number of economic tubers characters. Moreover, in Adira-4 genotypes, the tuber weight per plant characters had a significant positive correlation with the number of economic tubers.

The same result was also reported by Khumaida et al [7] that number of tubers per plant character and number of economic tuber on Ratim, Malang-4, and UJ-5 cassava 
TABLE 2: Correlation score between several characters on cassava mutant $M_{1} V_{2}$ generation.

\begin{tabular}{|c|c|c|c|c|c|}
\hline & $\mathrm{PH}$ & HFB & TW & NT & NET \\
\hline \multicolumn{6}{|c|}{ Jame-jame } \\
\hline HFB & $0.576^{* *}$ & & & & \\
\hline TW & 0.416 & -0.094 & & & \\
\hline NT & 0.360 & -0.179 & 0.242 & & \\
\hline NET & 0.168 & -0.211 & 0.309 & $0.567^{\star *}$ & \\
\hline $\mathrm{CT}$ & -0.097 & 0.072 & -0.028 & -0.262 & -0.045 \\
\hline \multicolumn{6}{|c|}{ Adira-4 } \\
\hline HFB & $0.664^{* *}$ & & & & \\
\hline TW & -0.310 & -0.446 & & & \\
\hline NT & -0.181 & -0.034 & 0.324 & & \\
\hline NET & -0.353 & -0.209 & $0.584^{* *}$ & $0.607^{* *}$ & \\
\hline $\mathrm{CT}$ & -0.299 & -0.286 & 0.309 & -0.115 & 0.344 \\
\hline
\end{tabular}

**: significant correlation on $\alpha=1 \%$, * significant correlation on $\alpha=5 \%$, PH: plant height; HFB: height to the first branching, TW = tuber weight per plant. NT = number of tuber per plant, $\mathrm{NET}=$ number of economic tuber per plant, CT: cortex thickness.

TABLE 3: Variability of tuber character of several potential mutant on $M_{1} V_{2}$ generation.

\begin{tabular}{|c|c|c|}
\hline \multirow[t]{2}{*}{ Genotype } & \multicolumn{2}{|c|}{ Tuber } \\
\hline & Type & Shape \\
\hline$V_{1} D_{1-2}(2)$ & sessile & $\begin{array}{c}\text { conical- } \\
\text { cylindrical }\end{array}$ \\
\hline$V_{5} D_{1}-(2)$ & mixed & conical \\
\hline$V_{5} D_{1-2(2)}$ & mixed & conical \\
\hline$V_{5} D_{1-3}(2)$ & mixed & conical \\
\hline$V_{5} D_{1-3}(3)$ & sessile & $\begin{array}{l}\text { conical- } \\
\text { cylindrical }\end{array}$ \\
\hline$V_{5} D_{1}-4(3)$ & mixed & Cylindrical \\
\hline$V_{5} D_{2}-(1)$ & pedunculate & irregular \\
\hline$V_{5} D_{2}-2(2)$ & pedunculate & conical \\
\hline$V_{5} D_{2}-6(2)$ & Sessile & conical \\
\hline
\end{tabular}

\begin{tabular}{|c|c|c|c|}
\hline \multicolumn{3}{|c|}{ Color of Tuber } & Easy of peeling \\
\hline Epidermis & Parenchyma & Cortex & \\
\hline light brown & beige & Light red & easy \\
\hline Dark brown & white & Light red & easy \\
\hline Dark brown & White & Light red & easy \\
\hline Dark brown & white & Light red & easy \\
\hline Light brown & white & Light red & easy \\
\hline Dark brown & white & Light red & easy \\
\hline Light brown & white & Light red & easy \\
\hline Light brown & white & Light red & easy \\
\hline Dark brown & white & Light red & easy \\
\hline
\end{tabular}

genotypes showed a significant positive correlation with the tuber yield and stem diameter. This indicates that those three characters could be used for estimating the cassava yield potential (tuber weight). The all yield characters were very important and necessary to be improved for creating new variety of high yielding cassava in Indonesia. As mentioned by Ceballos et al. [5], that as traditional landraces are replaced by improved varieties, especially when accompanied by better agronomy, productivity and stability of production increase significantly.

Gamma ray irradiation treatment on stem cutting of Jame-jame and adira-4 genotypes also improved the variability of several tuber characters such as tuber type, tuber shape, color of tuber (epidermis, parenchyma, cortex), and easiness of peeling (Table 
3). The tuber type of several mutants $M_{1} V_{2}$ generation ie. Sessile, mixed, and pedunculate, while the tuber shape are conical, irregular, cylindrical, and conical-cylindrical. As mentioned by Khumaida et al (2015a), stated that in $M_{1} V_{2}$ generation mutant (UJ5), tuber shape dominated with cylindrical and $V_{3} D_{1}-2(1), V_{3} D_{2}-1(1)$ and $V_{3} D_{2}-4$ (1) has a conical tubers shape on plants from tip cuttings. Malang-4 Genotype have conicalcylindrical tuber shape, while the $M_{1} V_{1}$ generation occurs tuber shape diversity which are conical, conical-cylindrical, and cylindrical. Mutant tuber forms in $M_{1} V_{2}$ generation was dominated by cylindrical shape. From these results, it seem the genetic changes caused by physical mutation in cassava plants can alter the character of agronomic and chemical content of cassava randomly, so radiation treatment can give various results [8]. The gamma-ray irradiation may lead to diversity, which is caused by the interaction of genetic and environmental factors [9].

Based on the result above that had been presented in the Table 1, 2, and 3, which were obtained nine potential cassava mutants (1 mutant generated from Jame-jame and 8 mutants from Adira-4 genotype), namely: V1D1-2 (2), V5D1-(2), V5D1-2(2), V5D1$3(2), V_{5} D_{1}-3(3), V_{5} D_{1}-4(3), V_{5} D_{2}-(1), V_{5} D_{2}-2(2)$, and $V_{5} D_{2}-6(2)$. Stability analysis was conducted to obtain stable cassava mutants genetically (data not shown). Six stable cassava mutants that had been obtained, namely: $V_{5} D_{1}-(2), V_{5} D_{1}-2(2), V_{5} D_{1}-3(2)$, $V_{5} D_{1}-4(3), V_{5} D_{2}-2(2)$, and $V_{5} D_{2}-6(2)$. All stable cassava mutants were generated from Adira-4 genotype.

\section{Conclusion}

Gamma irradiation induced some morphological changes (ie. Plant height, height to the first branching, etc) and variability in yield characters of cassava mutants $M_{1} V_{2}$ generation. There are positive correlation between plant height, first branching height, tuber weight, number of roots, and number of economic roots. Based on tuber weight and number of economic tuber there were 9 potential mutants (putative). There were 6 potential stable mutants (putative) by first branching height, tuber weight, total number of tubers and total number of economies tuber namely: $V_{5} D_{1}-(2), V_{5} D_{1}-2(2)$, $V_{5} D_{1}-3(2), V_{5} D_{1}-4(3), V_{5} D_{2}-2(2)$, and $V_{5} D_{2}-6(2)$

\section{Acknowledgement}

The authors wish to acknowledge the Ministry of Research, Technology and Higher Education, Republic of Indonesia, for the funding of this research through Kerjasama Luar Negeri dan Publikasi Internasional (KLNPI) scheme at 2015. 


\section{References}

[1] Liu J., Zheng Q., Ma Q., Gadidasu K.K., Zhang P. 2011 Cassava genetic transformation and its application in breeding. J. Integr. Plant Biol. 53:552-569.

[2] FAO. 2010. FAOSTAT. (http://faostat.fao.org/).

[3] Stapleton G. 2012. Global starch market outlook and competing starch raw materials for starches by product segment and region. Cassava Starch World. 2012. Centre for Management Technology (CMT), Phnom Penh.

[4] Norton R.2014 Global starch market outlook and feedstock economics. Cassava World. Africa 2014. Centre for Management Technology (CMT), Lusaka.

[5] Ceballos, H, Kawuki, RS, Gracen, VE, Yencho, GC, and Hershey, CH. 2015. Conventional breeding, marker-assisted selection, genomic selection and inbreeding in clonally propagated crops: a case study for cassava. Theor Appl Genet. 128:16471667

[6] Khumaida N, Ardie SW, Dianasari M, and Syukur M. 2015a. Cassava (Manihot esculenta Crantz.) Improvement through Gamma Irradiation. Procedia Food Science 3:27-34.

[7] Khumaida N, Maharani S, Ardie SW. 2015b. The leaf color performance on several lines of cassava and its relation with tuber yield as early reference. Procedia Environmental Sciences. Vol 24: 39-46.

[8] Oyeyemi SM, Lawal A0. 2010. Reduction of cyanide content in cassava by gamma irradiation from CirusCobol (60) teletherapy machine. J Appl Sci. 5: 69-73

[9] Tofino A, Cabal D, Sanchez T, Ceballos H. 2011. Identification of radiation induced mutants of cassava (Manihot esculento Crantz.) using morphological and physicochemical descriptors. Agronomia Colombiana 29:179-188. 